\title{
A EVOLUÇÃO DA QUALIDADE DO EMPREGO NA AGROPECUÁRIA BRASILEIRA: UMA AVALIAÇÃO DO PERÍODO 1990 - 2010. ${ }^{1}$
}

\author{
Camila Pereira Brígido Rodrigues ${ }^{2}$ \\ José Márcio dos Santos ${ }^{3}$
}

\begin{abstract}
Resumo: Os setores rurais vêm passando por intensas modificações em seus cenários. A agropecuária brasileira, devido ao aumento de suas exportações e ao crescimento da produção para o mercado interno, contribui para o aumento da geração de empregos. Contudo, em decorrência das modificações tecnológicas e do avanço da urbanização, ocorreu uma mudança na dinâmica de trabalho deste setor, modificando suas relações internas de produção. Dentro deste contexto de seguidas alterações, este artigo analisa a qualidade do emprego na agropecuária brasileira dos anos de 1990 a 2010. Utilizando os dados da Relação Anual de Informações Sociais, do Ministério do Trabalho e Emprego, estimou-se o Índice de Qualidade do Emprego Formal para o setor agropecuário no período 1990 a 2010. Os resultados mostram avanço na escolaridade, contração salarial e padrões elevados de rotatividade, indicando substituição da mão de obra no setor por uma de melhor qualidade.
\end{abstract}

Palavras-Chave: Qualidade de emprego, Agropecuária, Economia Regional

\begin{abstract}
The rural segments are going through intense changes in their scenarios. Brazilian agriculture and cattle raising sectors, due to exports and production growth for the domestic market, contribute to job growth. However, due to technological changes and advancement of the urbanization, a change in the dynamics of labor in this sector has occurred, modifying their internal relations of production. In this context of changes, this paper analyzes the quality of employment in Brazilian agriculture in the years 1990-2010. Using data from the Relação Anual de Informações Sociais, from Ministry of Labor and Employment, the Formal Employment Quality Index was estimated in the agriculture sector in the period 1990-2010. Results demonstrate an advance in education, wage contraction and high standards of turnover, indicating replacement of labor in this segment.
\end{abstract}

Keywords: Employment quality, Agriculture and cattle raising sectors, Regional economy

1 Recebido em: 11/02/2014; Aceito em: 28/10/2014.

2 Bacharel em Ciências Econômicas pela Universidade Regional do Cariri - URCA. Email: camilabrigido@ hotmail.com

3 Professor Assistente da Universidade Regional do Cariri (URCA)

Mestre em Economia pela Universidade Federal da Paraíba (UFPB). Email: jmarcio.santos@hotmail.com 


\section{Introdução}

Os dados do IBGE (2014) mostram que vem aumentando o número de trabalhadores no setor agrícola brasileiro. Isto se deve ao processo de modernização da atividade agropecuária e à ampliação da produção agrícola. Juntando-se a tais modificações tem-se o crescimento acelerado da urbanização do país.

Embora se denotem diversas barreiras, assim como diversas situações conjunturais, a agropecuária brasileira vem apresentando um PIB crescente nas últimas duas décadas. Segundo Avellar e Vilela (2006, pag. 4) “... de 1990 a 2004, a taxa geométrica de crescimento do PIB agropecuário foi de 2,4 pontos percentuais, enquanto o PIB nacional expandiu-se apenas $1,11 \%$ ao ano".

A partir da década de 1960, inicia-se na economia brasileira um processo de modernização da agricultura, fundamentado na introdução de inovações tecnológicas que visavam a elevar a produtividade das culturas, levando a modificações na relação de composição da mão de obra, por meio da sua substituição por capital (GOODMAN; SORJ; WILKINSON, 1985 apud NASCIMENTO et al., 2008).

Essa modernização desmesurada, que renova a agricultura brasileira e se torna responsável pelas novas configurações do mercado de trabalho rural e urbano, gera, também, uma migração de pessoas do campo para a cidade. Segundo Nascimento et al. (2008), a mercantilização do espaço rural, com a aliança entre o capital industrial e as grandes propriedades de terra, foi responsável por uma nova estrutura produtiva, voltada fundamentalmente para o mercado externo, cada vez mais intensiva em capital.

Para Schneider (2007, p. 22) "à medida que as famílias conseguem ter um portfólio mais diversificado de opções de trabalho, tornando-se pluriativas, suas rendas tendem a se elevar, adquirir maior estabilidade, e as fontes tendem a se diversificar". 
Silva (1997, p. 25) diz que "o espaço rural não mais pode ser pensado apenas como um lugar produtor de mercadorias agrárias e ofertador de mão de obra. Além de ele poder oferecer ar, água, turismo, lazer, bens de saúde, possibilitando uma gestão multi-propósito do espaço rural, oferece a possibilidade de, no espaço local-regional, combinar postos de trabalho com pequenas e médias empresas".

As transformações ocorridas no meio rural afetaram a qualidade de emprego, pois nos anos de 1970 se exigia pouca qualificação, resultando em oportunidade de empregos dos recém-chegados do campo. Nos anos de 1980, eram poucas as chances de se arranjar emprego para os migrantes, principalmente os advindos do campo. Com a reestruturação produtiva nos anos de 1990, agravou-se ainda mais esse processo.

Em 1990, 14,91 milhões de pessoas obtinham seus rendimentos na agropecuária. Quatorze anos depois, com o deslocamento para outros setores da economia nacional de $14,7 \%$ do total de pessoas que, em 1990, se ocupavam da agropecuária, esse número cai para 12,71 milhões (AVELLAR; VILELA, 2006).

Leone, Maia e Baltar (2007) afirmam que a partir de 2003 o mercado de trabalho brasileiro começa a enfrentar uma fase mais favorável ao trabalhador, aumentando tanto a ocupação quanto a proporção de contratos formais. Essa tendência se manifesta também no mercado de trabalho nas áreas rurais.

Neste contexto, este trabalho busca avaliar a qualidade de trabalho no setor agropecuário nos anos de 1990 a 2010, com o objetivo de detectar o progresso/retrocesso ocorrido nesse período.

É evidente que não se pode negar o peso da atividade agrícola no meio rural, principalmente nas Regiões Norte e Nordeste. O que deve ficar claro é que, além de produtos agropecuários, o mundo rural criou outro tipo de visão, agregando a ele serviços, indústria e comércio. Nesse sentido, são inúmeros os trabalhos que fazem referência à qualidade de emprego no Brasil, em que se tem o reconhecimento do espaço rural 
não mais singularmente agropecuário, mas um espaço que, além das atividades rurais, vem cada vez mais atrelando atividades urbanas a seu meio. Contudo, diferentemente dos demais trabalhos, tem-se aqui como base de dados a RAIS. Este trabalho está dividido, além da introdução, em mais quatro partes, compreendendo referencial teórico, metodologia, resultados e discussões e conclusão.

\section{Metodologia}

Para a análise da qualidade do trabalho, foi utilizada neste trabalho a base de dados da Relação Anual de Informações Sociais - RAIS, do Ministério do Trabalho e Emprego - MTE. A metodologia utilizada constituiu no uso da RAIS para estimar o Índice de Qualidade do Emprego Formal (IQEF) ${ }^{4}$.

O uso da RAIS apresenta uma série de benefícios e desvantagens que merecem ser destacadas. Ela se constitui numa fonte de dados confiável por ser formada pelas declarações entregues pelos empregadores. Além disto, a especificação de algumas variáveis permite uma análise qualitativa com base nestes dados. Outra vantagem da RAIS está na possibilidade de promover desagregações por diversos critérios, mais especificamente, a desagregação setorial, seguindo o critério da CNAE 1.0 - Classificação Nacional da Atividade Econômica. Outra vantagem é o fato de a RAIS apresentar um elevado grau de uniformidade, o que possibilita a comparação de seus dados ao longo do tempo. Além disto, ela é de rápido processamento e tabulação de dados, permitindo interpretação imediata.

A principal desvantagem da RAIS está no fato de ela só abranger o lado formal da economia, não captando relações contratuais de caráter informal. Esta é sua principal limitação, uma vez que se reconhece um

4 A presente metodologia foi adaptada de Campos (2000). A referida autora utiliza quatro variáveis de analise que são: grau de instrução, rotatividade, concentração salarial e média salarial. Esta última não foi usada neste trabalho por ter efeito semelhante ao indicador de concentração salarial. Desta forma, o presente trabalho utiliza três variáveis analíticas. 
alto grau de informalidade na economia brasileira. Outra desvantagem está no fato de que, apesar de serem declaradas pelos próprios agentes, a veracidade destas informações não é ratificada pelo MTE, o que pode gerar distorções, em algum momento, quanto à análise dos resultados. Finalmente, os dados podem apresentar distorções em virtude da ausência das informações das empresas não declarantes. Um terceiro problema da RAIS é que, como ela utiliza o emprego como variável base, ela deixa passar questões de distorções e diferenças tecnológicas e de produtividade entre as regiões.

Uma vez conhecida a ocorrência de transformações estruturais no setor agropecuário nacional, faz-se necessário averiguar os efeitos sobre a qualidade do trabalho realizado nestes estabelecimentos, permitindo visualizar a dinâmica das mudanças impostas aos seus trabalhadores. Para tanto, o instrumento utilizado será o Índice de Qualidade do Emprego Formal (IQEF), similar ao utilizado na determinação do Índice de Desenvolvimento Humano (IDH), usado pela Organização das Nações Unidas (ONU), que permite acompanhar a evolução da qualidade do trabalho analisando a dinâmica de algumas das suas principais variáveis.

Neste trabalho, as variáveis a serem consideradas no cálculo serão: grau de instrução, rotatividade e concentração salarial. Cada variável será convertida em um índice particular por interpolação linear, variando na ordem de 0 e 1 , ou 0 a $100 \%$, que será calculado individualmente obedecendo à seguinte expressão:

$$
I n d_{i}=\frac{V l r_{o}-V l r_{p}}{V l r_{m}-V l r_{p}}
$$

Em que $V l r_{o}$ se refere ao valor observado do indicador; $V l r_{p}$ é o pior valor possível de ser registrado; e $V l r_{m}$ expressa o melhor valor esperado para a variável.

Como pode ser observado, a interpolação linear consiste em subtrair da variável observada o pior valor possível esperado e dividi-lo pela 
subtração entre o melhor e o pior valor possível esperado para esta mesma variável.

Com respaldo nesta metodologia, a construção dos índices obedeceu ao seguinte critério:

1. Índice de escolaridade: dado pelo percentual dos trabalhadores com escolaridade igual ou superior ao segundo grau completo (ou ensino médio), com o cálculo variando entre zero e $100 \%$.

2. Índice de rotatividade da mão de obra: obtido com base no número total de admitidos em relação ao número total de empregados no ano de referência, sendo que sua variação pode estar entre 5\% e 100\%.

3. Índice de concentração salarial: expresso pelo percentual de empregados que recebem acima de dois salários mínimos em relação ao total de trabalhadores empregados, tendo como limites zero e $100 \%$.

Admitiu-se que os piores e melhores valores esperados estejam em pontos extremos da distribuição de probabilidade. Desta forma, admitindo que o pior valor possível seja a não ocorrência da variável, então ele assume o valor zero. Por outro lado, os melhores valores esperados serão a ocorrência absoluta da variável, assumindo assim o valor máximo de 1, equivalente a $100 \%$. Apesar de ambos os limites serem valores de ocorrência rara, eles são probabilisticamente possíveis. $\mathrm{O}$ fato de o ponto mínimo da taxa de rotatividade ser de 5\% significa a aceitação deste valor como sendo uma taxa de rotatividade mínima existente numa economia ${ }^{5}$. A exceção foi feita apenas para a variável salário médio, que está definida entre o limite inferior de um salário mínimo e o limite superior de dez salários mínimos.

A explanação dos resultados obtidos pelos índices segue duas interpretações distintas. Para os índices referentes à concentração de renda, escolaridade e concentração salarial, quanto mais próximos

5 Para mais detalhes, ver Prates (1997). 
os resultados estiverem de 1 , eles indicam aumento da incidência da variável analisada, significando melhoria na qualidade do emprego dentro daquele setor. Por outro lado, quanto mais próximos de zero estiverem os resultados, mais degradante será a condição do emprego. Interpretação contrária é feita para o índice de rotatividade. Quanto mais próximos de 1 estiverem os índices de rotatividade, maior será sua incidência, sendo interpretados como redução da qualidade do emprego; enquanto valores próximos de zero significam queda na incidência desta variável, indicando melhorias nas condições do emprego.

Uma vez construído cada índice individual, a determinação do IQEF obedeceu à média aritmética simples dos três índices anteriormente citados, sendo expresso por:

$$
I Q E F=\frac{\operatorname{Ind}_{E d u c .}+\operatorname{Ind}_{{ }_{\text {Rot. }}}+\text { Ind }_{{ }_{\text {Conc.Sal. }}}}{3}
$$

Ancorado nos procedimentos metodológicos descritos, foram elaborados um IQEF e seus índices componentes para o setor analisado na tentativa de detectar particularidades existentes na reestruturação de ambos os setores, bem como suas possíveis consequências sobre a qualidade do trabalho.

\section{Resultados e discussões}

A análise da qualidade de emprego foi feita segundo a metodologia do Índice de Qualidade do Emprego Formal (IQEF), calculado para o setor em estudo com base nos dados da RAIS (Relação Anual de Informações Sociais), entre o período de 1990 a 2010, referente às regiões geográficas, além do Brasil, representado como sendo o resultado total. Conforme descrito na metodologia deste estudo, o IQEF é resultado da média de três indicadores referentes ao nível educacional, rotatividade e concentração salarial. 
A avaliação da qualidade do emprego é resultado do comportamento qualitativo da mão de obra empregada nas atividades agropecuárias no país. Entretanto, a variação quantitativa aponta comportamentos distintos em níveis regionais (Tabela 1).

Tabela 1 - Taxa de crescimento do emprego agropecuário por região geográfica em termos percentuais

\begin{tabular}{lllllll}
\hline & Norte & Nordeste & Sudeste & Sul & Centro-Oeste & Total \\
\hline $1990-2000$ & $120,8 \%$ & $206,7 \%$ & $172,8 \%$ & $164,1 \%$ & $338,9 \%$ & $187,5 \%$ \\
$2000-2010$ & $210,6 \%$ & $39,2 \%$ & $11,7 \%$ & $22,9 \%$ & $89,0 \%$ & $31,5 \%$ \\
$1990-2010$ & $585,8 \%$ & $327,0 \%$ & $204,7 \%$ & $224,4 \%$ & $729,4 \%$ & $277,9 \%$ \\
\hline
\end{tabular}

Fonte: Elaboração própria, tendo por base dados da RAIS.

Estes valores cresceram em percentuais relativos distintos, como pode ser visualizado na Tabela 1. Em termos regionais, houve uma dinâmica de crescimento distinta com tendências de comportamentos bastante claras. É o caso da Região Centro-Oeste, que apresentou crescimento do volume de emprego agropecuário em valor superior à média de crescimento nacional em todos os períodos analisados, especialmente no período 1990-2010. Em segundo lugar, em termos de desempenho, está a Região Nordeste, que também apresentou crescimento em seu contingente de empregados no setor, mas em escala menor que a Região Centro-Oeste, ainda assim superior à média nacional. As regiões $\mathrm{Sul}$ e Sudeste, por sua vez, mostraram tendência de redução do emprego do setor agropecuário, pois cresceram em valores inferiores aos da média nacional. Já a dinâmica da Região Norte é distinta, pois seu crescimento no período 1990-2000 é inferior à média nacional, enquanto no período 2000-2010 e na série entre 1990-2010, o resultado mostra crescimento superior àquele apresentado pelo país como um todo.

A diferença entre as taxas de crescimento regionais do emprego promoveu realocação espacial do emprego agropecuário, alterando a participação regional na alocação do emprego agropecuário ao longo do tempo (Tabela 2). 
Tabela 2 - Participação regional percentual sobre o emprego agropecuário nacional

\begin{tabular}{cccccc}
\hline & Norte & Nordeste & Sudeste & Sul & Centro-Oeste \\
\hline $\mathbf{1 9 9 0}$ & $2,9 \%$ & $14,9 \%$ & $55,7 \%$ & $18,8 \%$ & $7,7 \%$ \\
$\mathbf{1 9 9 5}$ & $2,0 \%$ & $16,2 \%$ & $54,6 \%$ & $18,1 \%$ & $9,1 \%$ \\
$\mathbf{2 0 0 0}$ & $2,2 \%$ & $15,9 \%$ & $52,9 \%$ & $17,3 \%$ & $11,8 \%$ \\
$\mathbf{2 0 0 5}$ & $4,2 \%$ & $17,7 \%$ & $47,8 \%$ & $15,9 \%$ & $14,3 \%$ \\
$\mathbf{2 0 1 0}$ & $5,2 \%$ & $16,8 \%$ & $44,9 \%$ & $16,2 \%$ & $16,9 \%$ \\
\hline
\end{tabular}

Fonte: Elaboração própria, tendo por base dados da RAIS.

Os dados sobre o emprego nacional mostram correlação entre crescimento do emprego e participação regional. Assim, as regiões que apresentaram taxa de crescimento superiores à média nacional aumentaram sua participação no montante de emprego nacional. Nesta dinâmica, a Região Norte ampliou sua participação de 2,9\%, em 1990, para 5,2\%, em 2010; a Região Nordeste saiu de 14,9\%, em 1990, para 16,8\%, em 2010; e a Região Centro-Oeste aumentou sua participação de forma expressiva, saindo de 7,7\%, em 1990, para 16,9\%, em 2010. Outro dado bastante expressivo é a redução da participação da Região Sudeste no emprego agropecuário nacional. Esta região, que detinha 55,7\% do emprego do setor em 1990, vê sua participação cair para 44,9\%, em 2010. A Região Sul também mostrou queda em termos de participação, mas de forma mais modesta, saindo de um valor de $18,8 \%$, em 1990, para 16,2\%, em 2010. Desta forma, fica evidente que, em termos quantitativos, houve expressiva mudança nos padrões de emprego agropecuário no Brasil nas últimas duas décadas, sinalizado que a expressão do emprego vem acompanhada de alterações de caráter regional em sua composição.

A mudança quantitativa apresentada pelo comportamento do emprego agregado e regional também foi acompanhada de uma mudança qualitativa no perfil do emprego agropecuário, conforme pode ser visualizado nos indicadores que compõem o IQEF. Em relação ao grau de concentração salarial estimado, percentual de trabalhadores que ganham acima de dois salários, o indicador calculado mostra forte redução no número de 
trabalhadores que ganham rendimentos acima de dois salários mínimos (Gráfico 01).

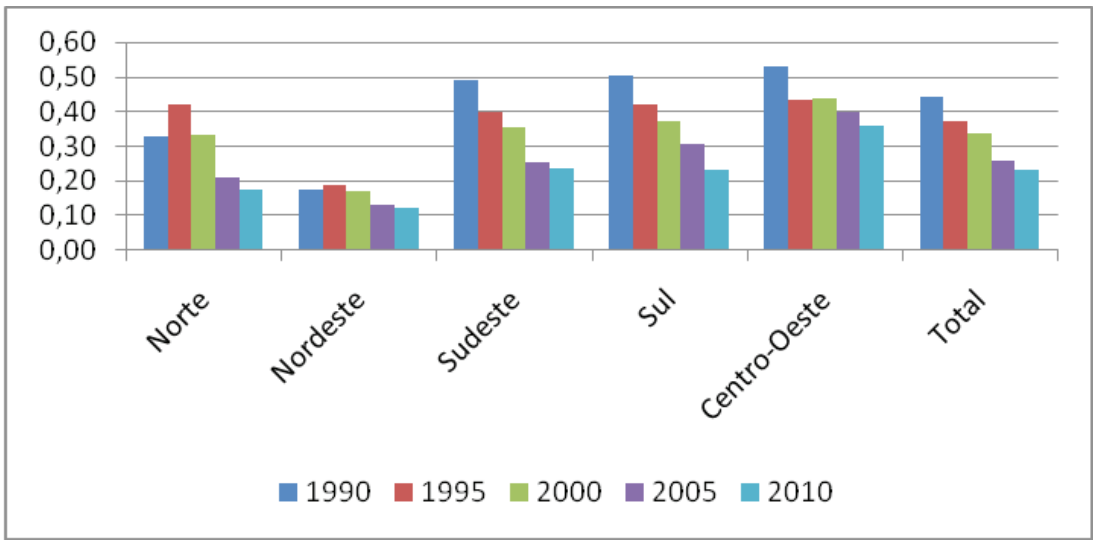

Gráfico 1- Evolução do indicador concentração salarial

Fonte: Elaboração própria, tendo por base dados da RAIS.

Os dados mostram que o percentual de trabalhadores do setor agropecuário que ganham acima de dois salários mínimos vem caindo em todas as Regiões do Brasil. As maiores contrações foram observadas nas Regiões Sudeste e Sul, que apresentaram redução de 25 e 27 pontos percentuais, respectivamente, valores superiores ao patamar de redução nacional, que foi de 21 pontos percentuais. Assim, o Sudeste saiu de um indicador de 0,49, em 1990, para 0,24, em 2010; enquanto o Sul foi de 0,50, em 1990, para 0,23 , em 2010. A contração foi registrada também nas regiões do Centro-Oeste, cujo indicador caiu de 0,53 para 0,36, entre 1990-2010; e na Região Norte, cujo indicador caiu de 0,33 para 0,17 , no mesmo período. A Região Nordeste também mostrou contração no número de trabalhadores com ganhos maiores que dois salários mínimos, mas numa escala menor, de 0,18 para 0,12. Contudo, deve-se ressaltar que, no caso do Nordeste, os valores de toda a série observada estão abaixo dos apresentados pelas demais regiões, justificando a menor variação. 
Dentro deste contexto, levanta-se a hipótese da concentração da mão de obra em atividades com baixa remuneração, muitas vezes concentrada em faixa de até dois salários mínimos, como ratificam os dados presentes na Tabela 3.

Tabela 3- Distribuição da mão de obra segundo a faixa de remuneração

\begin{tabular}{lll} 
Faixa de Remuneração & 1990 & 2010 \\
Até 0,50 & $0,14 \%$ & $0,28 \%$ \\
0,51 a 1,00 & $7,32 \%$ & $10,29 \%$ \\
1,01 a 2,00 & $45,66 \%$ & $62,32 \%$ \\
2,01 a 3,00 & $21,99 \%$ & $16,08 \%$ \\
3,01 a 4,00 & $9,64 \%$ & $5,00 \%$ \\
4,01 a 5,00 & 4,655 & $1,72 \%$ \\
5,01 a 7,00 & $4,41 \%$ & $1,29 \%$ \\
7,01 a 10,00 & $1,72 \%$ & $0,64 \%$ \\
10,01 a 15,00 & $1,00 \%$ & $0,35 \%$ \\
15,01 a 20,00 & $0,43 \%$ & $0,11 \%$ \\
Mais de 20,00 & $0,56 \%$ & $0,14 \%$ \\
\{n class & $2,43 \%$ & $1,72 \%$ \\
Total & $100,00 \%$ & 100,0000 \\
\hline
\end{tabular}

Fonte: Elaboração própria, tendo por base os dados da RAIS.

Tal afirmativa se deve ao aumento do percentual de trabalhadores que passaram a ganhar a entre 1(um) e 2(dois) salários mínimos, que, em 1990, correspondiam a 45,66\% dos empregados na agropecuária no período, passando para 62,32\% em 2010. Paralelamente, houve contração dos empregados com remuneração acima de 3 (três) salários mínimos em todas as faixas de remuneração analisadas, sendo que o somatório destas faixas caiu de 24,87\%, em 1990, para 11\%, em 2010.

Em relação ao indicador referente ao nível educacional, que mede o percentual de trabalhadores que têm pelo menos o segundo grau completo (ensino médio), sobre o número total de funcionários empregados, ele 
apresentou expressivo crescimento ao longo dos períodos analisados. A trajetória dos valores apresentados pode ser vista no Gráfico 02. Em todas as regiões foi registrado aumento do indicador de escolaridade, ocorrendo divergência no grau da variação entre as regiões.

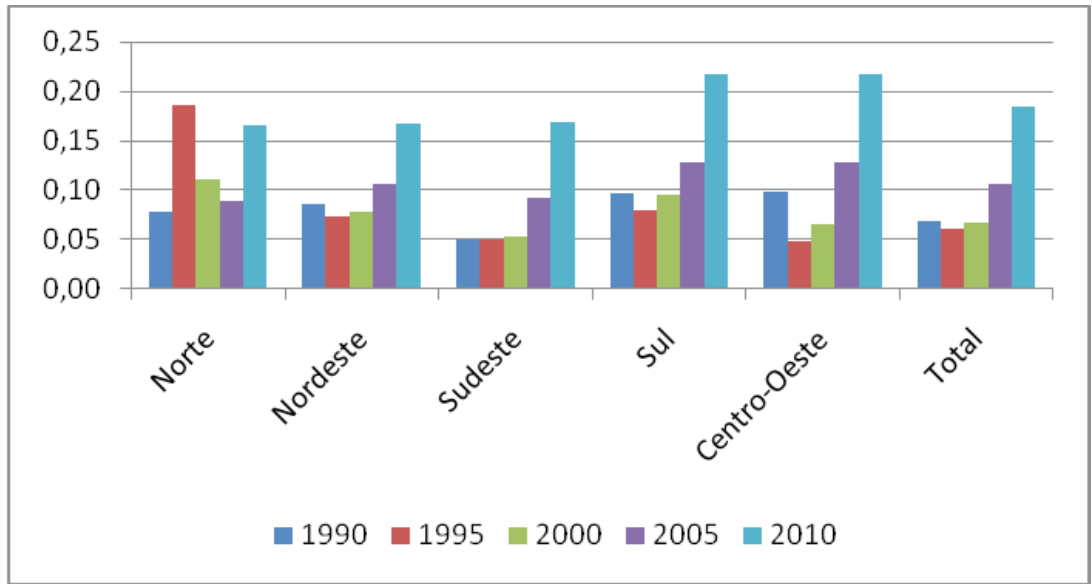

Gráfico 2- Evolução do indicador escolaridade

Fonte: Elaboração própria, tendo por base dados da RAIS.

Em termos de comportamento regional, as Regiões Norte, Nordeste e Sudeste apresentaram resultados muito semelhantes, com indicadores iniciais de $0,08,0,8$ e 0,05 , respectivamente, tendo como indicador final valor de 0,17 , expressando melhoria no nível educacional no emprego destas regiões. Por sua vez, Sul e Centro-Oeste mostraram evolução superior, pois seus indicadores partem de 0,1, em 1990, e atingem o valor de 0,22 . Ou seja, houve elevação da escolaridade em patamar superior ao das três primeiras regiões analisadas.

A escolaridade da mão de obra empregada no setor apresentou avanços na medida em que se reduziu o número de trabalhadores analfabetos e com o ensino fundamental incompleto. Em paralelo, houve aumento do 
percentual de trabalhadores nos demais graus de instrução, em especial aqueles com ensino fundamental e médio completo, cujas taxas de crescimento foram as mais expressivas (Tabela 4).

Tabela 4 - Composição percentual da escolaridade da mão de obra a nível nacional

\begin{tabular}{lcc}
\hline Grau de instrução & 1990 & 2010 \\
Analfabeto & $9,03 \%$ & $3,53 \%$ \\
Fundamental Incompleto & $76,24 \%$ & $53,35 \%$ \\
Fundamental completo & $4,49 \%$ & $15,93 \%$ \\
$2^{\circ}$ Grau Incompleto & $2,42 \%$ & $7,27 \%$ \\
$2^{\circ}$ Grau Completo & $4,27 \%$ & $16,59 \%$ \\
Superior Incompleto & $0,79 \%$ & $0,85 \%$ \\
Superior Completo & $1,81 \%$ & $2,42 \%$ \\
Pós-Graduação & $0,95 \%$ & $0,07 \%$ \\
Total & $100,00 \%$ & $100,00 \%$ \\
\hline
\end{tabular}

Fonte: Elaboração própria, tendo por base dados da RAIS

A análise do indicador de rotatividade apresentou aspectos particulares da dinâmica da mão de obra deste setor. Sua compreensão passa inicialmente pela flutuação do emprego agregado, a nível regional. A série de dados da Tabela 5 mostra a evolução do número de empregos na agropecuária no Brasil. Apesar de ser registrado um crescimento absoluto da mão de obra, há grandes flutuações, tanto a nível regional quanto nacional. 
Tabela 5 - Evolução do numero de empregos formais no setor agropecuário brasileiro por região geográfica

\begin{tabular}{ccccccc}
\hline & Norte & Nordeste & Sudeste & Sul & Centro-Oeste & Total \\
1990 & 10.695 & 55.420 & 207.895 & 70.224 & 28.726 & 372.960 \\
$\mathbf{1 9 9 5}$ & 20.020 & 160.782 & 542.484 & 179.402 & 89.957 & 993.834 \\
$\mathbf{2 0 0 0}$ & 23.614 & 169.994 & 567.134 & 185.449 & 126.080 & 1.072 .271 \\
$\mathbf{2 0 0 5}$ & 54.990 & 232.456 & 626.981 & 208.898 & 186.995 & 1.310 .320 \\
$\mathbf{2 0 1 0}$ & 73.347 & 236.659 & 633.494 & 227.830 & 238.267 & 1.409 .597 \\
\hline
\end{tabular}

Fonte: Elaboração própria, tendo por base dados da RAIS.

No contexto do período analisado, o número de empregos cresceu ao longo da série. Porém, a diferença no crescimento destes valores a nível regional denota oscilação ao longo da série. Isto porque, apesar de os valores serem crescentes, eles encobrem os desligamentos existentes no processo de alocação dos empregos, levando a uma constante alteração da composição da mão de obra do setor. Estes fatores influenciam os resultados apresentados pelo indicador de rotatividade, que mostra a rotatividade efetiva registrada no período. Estes números são mostrados no Gráfico 03.

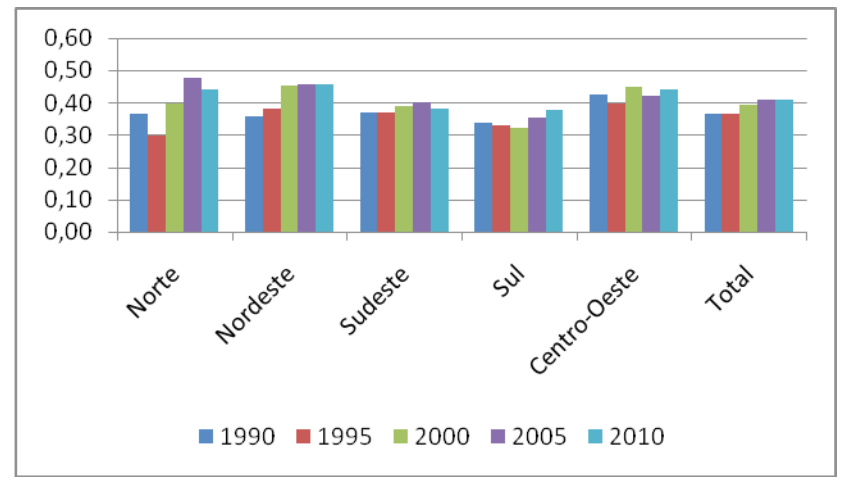

Gráfico 3 - Evolução do indicador rotatividade

Fonte: Elaboração própria, tendo por base dados da RAIS. 
$\mathrm{O}$ indicador rotatividade mostrou-se extremamente afetado pelas alterações no volume da mão de obra, que podem ser deduzidas da Tabela 5 disposta anteriormente. Neste sentido, a rotatividade cresceu em todas as regiões analisadas em termos totais ou nacionais. A Região Centro-Oeste apresentou a maior média de rotatividade de toda a série. Por sua vez, a Região Nordeste apresentou a maior elevação absoluta no indicador, saindo de 0,36 para 0,46. Já o Sudeste e o Sul apresentaram certa estabilidade em seus indicadores, ambos os valores finais permanecendo na faixa de 0,38 . A análise da rotatividade é baseada na faixa de oscilação e manutenção do próprio indicador e expressa a atual condição da dinâmica empregatícia do setor.

Segundo Campos (2000), rotatividade na faixa de 30\% é considerada relativamente alta pelas empresas, pois indica que a mão de obra não está se mantendo nos postos de trabalho gerados. Tal percentual revela aqui a existência de fenômenos implícitos. Em primeiro lugar, estes valores comprovam que as empresas estão à procura de uma mão de obra mais qualificada para seus quadros de pessoal. Somados ao registro do aumento da escolaridade, tem-se que a rotatividade foi empregada como forma de promover a substituição da mão de obra existente por uma mais qualificada. Em segundo lugar, estes números também podem ser indício de que as condições de trabalho podem não estar sendo agradáveis, refletindo-se assim na alta rotatividade apresentada pela busca constante de novos empregos por parte dos trabalhadores.

Uma vez tendo definidos os valores dos três indicadores, procurouse estimar o valor do Índice da Qualidade do Emprego Formal (IQEF). Com respaldo na média aritmética obtida pelos três indicadores anteriormente citados, tem-se a construção do IQEF para o setor estudado. O Gráfico 04 mostra a evolução completa do IQEF do setor da agropecuária ao longo da série estudada. 


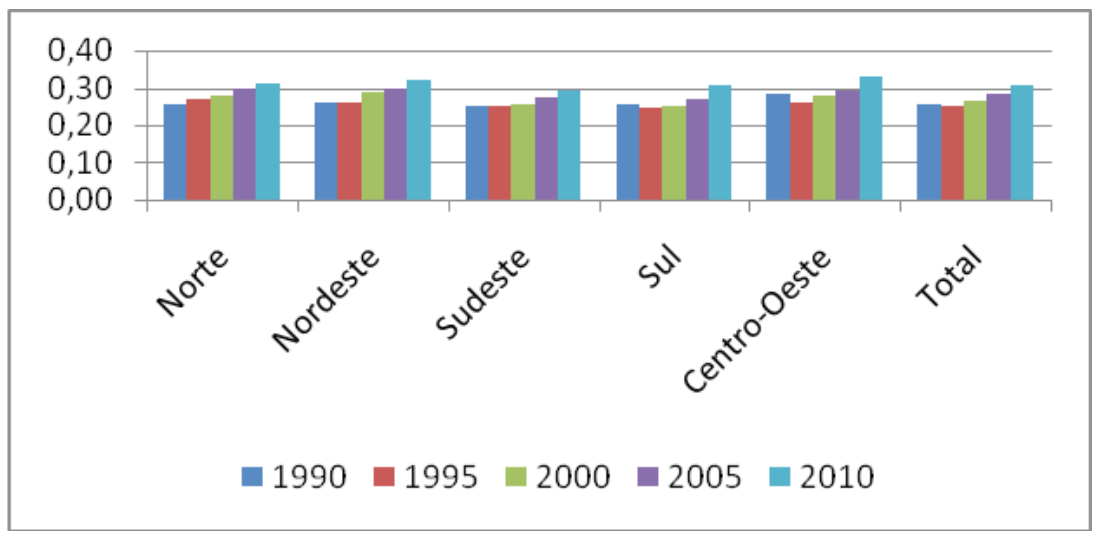

Gráfico 4- Evolução do IQEF

Fonte: Elaboração própria, tendo por base dados da RAIS.

Os dados mostram que, em termos gerais, a qualidade de trabalho na agropecuária evoluiu ao longo dos períodos estudados, apresentando comportamento padronizado em todas as regiões geográficas, haja vista o resultado atribuído à dinâmica dos indicadores obtidos anteriormente. Ou seja, todas as regiões apresentaram avanços e melhorias no indicador escolaridade, contrações no indicador concentração salarial e manutenção da taxa de rotatividade em níveis relativamente altos. A inter-relação dos indicadores pode sugerir a substituição da mão de obra ocupada, haja vista o elevado indicador de rotatividade, por uma mão de obra de maior escolaridade, sugerida pelo indicador de escolaridade, em que esta mesma mão de obra, em função das limitações do mercado de trabalho, estaria aceitando salários menores, justificando o indicador de concentração salarial decrescente.

Diferentemente do que tem sido identificado em setores como comércio, serviços e até mesmo na indústria, que vêm indicando uma troca dos trabalhadores mais velhos por trabalhadores mais jovens, a substituição da mão de obra ocorrida no âmbito da agropecuária pode estar sendo feita por pessoas advindas do mesmo setor, com maior faixa etária. Analisando a composição, segundo a faixa etária, observa-se que esta 
mão de obra vem se concentrando na faixa etária acima de 25 anos, como pode visto na Tabela 6 .

Tabela 6 - Composição dos trabalhadores da agropecuária segundo faixa etária a nível nacional

\begin{tabular}{ccc}
\hline Faixa Etária & 1990 & 2010 \\
10 A 14 & $0,74 \%$ & $0,00 \%$ \\
15 A 17 & $6,64 \%$ & $0,73 \%$ \\
18 A 24 & $23,63 \%$ & $14,91 \%$ \\
25 A 29 & $16,74 \%$ & $15,55 \%$ \\
30 A 39 & $25,36 \%$ & $29,69 \%$ \\
40 A 49 & $14,48 \%$ & $22,93 \%$ \\
50 A 64 & $10,30 \%$ & $15,19 \%$ \\
65 OU MAIS & $1,16 \%$ & $0,99 \%$ \\
\{n class & $0,96 \%$ & $0,00 \%$ \\
Total & $100,00 \%$ & $100,00 \%$ \\
\hline
\end{tabular}

Fonte: Elaboração própria, tendo por base dados da RAIS.

Segundo os dados, a faixa etária entre 18-24 anos, considerada a faixa jovem da população ativa, vem diminuindo sua participação no emprego da agropecuária, haja vista que em 1990 ela representava 23,63\% da mão de obra deste setor, ao passo que em 2010, 14,91\% dos empregos ocupados. Entretanto, todas as categorias de faixa etária superior a 25 anos apresentaram crescimento da sua participação no emprego da agropecuária nacional. Estas categorias que, em 1990 somavam $68,99 \%$ dos empregos da agropecuária, em 2010, representavam 84,35\% dos empregos ocupados. Assim, supõe-se que deve estar havendo um processo de qualificação interna na agropecuária feita entre os próprios empregados, haja vista que não está havendo entrada de jovens neste segmento. Percebe-se então a manutenção da composição da mão de obra, majoritariamente formada por um grupo específico de trabalhadores. Desta forma, reforça-se a hipótese de que o trabalho nestes setores tem sido preenchido por pessoas mais qualificadas, internas ao setor. 
Apesar de o IQEF ter mostrado um leve crescimento ao longo da série, uma análise mais criteriosa deve ser feita sobre seus resultados. Individualmente, os indicadores obtidos têm um poder explicativo para as variáveis analisadas, permitindo diagnosticar sua situação ao longo da série temporal. Porém, esta análise perde em poder explicativo quando se calcula o índice. Mesmo assim, o IQEF permite uma avaliação da situação do trabalho onde for utilizado como instrumental metodológico. Através dos números obtidos pelos indicadores parciais, podemos inferir que possa ter havido emprego de políticas de substituição da mão de obra como forma de promover a qualificação dos quadros de funcionários nas empresas pela contratação de trabalhadores mais escolarizados. Porém, estas práticas são baseadas também na substituição dos funcionários atuais por outros por um salário cada vez menor, tendência apontada pelos indicadores salário e concentração salarial.

\section{Considerações finais}

Com a finalidade de analisar a qualidade do setor agropecuário brasileiro nos anos de 1990 a 2010, foi construído o Índice de Qualidade do Emprego Formal (IQEF), que possibilitou a comparação da qualidade do emprego na agropecuária entre as regiões brasileiras.

Os resultados apontam que tanto a Região Centro-Oeste como a Nordeste estão gerando mais empregos que a média nacional para o setor agropecuário, contrastando com as demais regiões do país. Gerase uma curiosidade em relação à Região Norte do país, que, no período de 1990-2000, não atinge a média nacional, porém em todas as outras avaliações permanece acima deste patamar.

Outro resultado importante é a nova alocação espacial do emprego agropecuário, notando-se relação direta entre o crescimento do emprego nas regiões de destaque e o montante nacional, ou seja, ocorre aumento de pessoas empregadas nas áreas de destaque no setor agropecuário, conforme apontado por Leone, Maia e Baltar (2007). 
A mudança quantitativa apresentada pelo comportamento do emprego agregado e regional também foi acompanhada de uma mudança qualitativa no perfil do emprego agropecuário.

Nota-se redução da remuneração em todas as regiões do Brasil, levantando o questionamento se a produção agropecuária se desvalorizou devido ao processo de urbanização, levando assim à redução da mão de obra pertencente à zona rural do país, ou se, devido à mecanização, vinda com a urbanização, tal mão de obra passou a ser tão desvalorizada. Levando em consideração o nível educacional em todas as regiões, foi registrado aumento do indicador de escolaridade, ocorrendo divergência no grau da variação entre as regiões. Quanto ao indicador de rotatividade, ele apresentou aspectos singulares da dinâmica da mão de obra deste setor, podendo as constantes alterações na sua composição ser creditadas aos fatores apontados por Silva (1997) e Schneider (2007).

Analisando os indicadores e calculando o IQEF, chega-se à conclusão de que todas as regiões apresentaram avanços e melhorias no indicador escolaridade, contrações no indicador concentração salarial e manutenção da taxa de rotatividade em níveis relativamente altos. A inter-relação entre os indicadores pode sugerir estar ocorrendo substituição da mão de obra ocupada, haja vista o elevado indicador de rotatividade, por uma mão de obra de maior escolaridade, sugerida pelo indicador de escolaridade, em que esta mesma mão de obra, devido às limitações do mercado de trabalho, estaria aceitando salários menores, justificando o indicador de concentração salarial decrescente.

Os resultados dos IQEFs alcançados para o emprego no Brasil fornecem subsídios dignos de atenção no que se refere à formulação de políticas públicas de produção de emprego e renda para a população que reside na zona rural. Se, por um lado, o estímulo às atividades que tem maior remuneração em outros setores (comércio, serviço, indústria) pode ter efeitos positivos na melhoria da qualidade do emprego e, consequentemente, das condições de vida dos trabalhadores; por outro, ainda há o desafio, que é a atribuição de políticas que forneçam 
mais empregos agrícolas e, ao mesmo tempo, melhoria das condições trabalhistas dos empregados neste setor.

\section{Referências}

AVELLAR, Sérgio; VILELA, Pierre. Evolução do número de pessoas ocupadas na agropecuária brasileira no período de 1990 a 2004. Revista de Política Agrícola, Brasília, 2006.

CAMPOS, Mabel Jaqueline Carmona de. Processo de abertura econômica, competitividade e reestruturação produtiva da indústria têxtil brasileira: uma análise comparativa das regiões nordeste e sul (1985 - 1998). 2000. Dissertação (Mestrado em Economia) - João Pessoa: CME/UFPB, 2000.

FIGUEIREDO, Nelly Maria Sansígolo de; BRANCHI, Bruna Angela; SAKAMOTO, Camila Strobl. Evolução da qualidade do emprego rural no Brasil e regiões entre 2004 e 2009 sob uma perspectiva de gênero. PESQUISA \& DEBATE, SP, volume 23, número 2(42) pp. 223-245, jul.-dez. 2012.

IBGE. Atlas do Censo 2010. Disponivelem :http:/www.ibge.gov.br/ home/estatistica/populacao/censo2010/default_atlas.shtm. Acesso em:20/09/2014.

LEONE, Eugenia Troncoso; MAIA, Alexandre Gori; BALTAR, Paulo de Andrade.Formalização e Informalização do emprego no Brasil rural. In: XLV Congresso da SOBER: Conhecimentos para Agricultura do futuro, 2007, Londrina.

NASCIMENTO, C.A.; OLIVEIRA, R. B.; SOUTO, I. J. G. MENDES, S. R. A Qualidade do Emprego Rural na Região Nordeste (2002 e 2005). Revista ABET, v. VII, n.2. 2008. 
PRATES, M. C. R.. Radiografia do emprego formal no Brasil a partir da RAIS. Texto para discussão FGV/IBRE/CEEG, nº 10; abril, 1997.

RELAÇÃO ANUAL DE INFORMAÇÃO SOCIAL - RAIS. Disponível em: <http://www.rais.gov.br> acesso em: Julho de 2013.

SCHNEIDER, S. A importância da pluriatividade para as políticas públicas no Brasil. Revista de política Agrícola 3: 15-34, 2007.

SILVA, José Graziano da .O novo rural brasileiro. Revista Nova economia, Belo horizonte. Maio,1997. 
REVISTA DE ECONOMIA E AGRONEGÓCIO, VOL.11, $N^{\circ} 3$ 